\title{
Interaction of the neurotransmitter, neuropeptide Y (NPY), with phospholipid membranes: Film balance and fluorescence microscopy studies
}

\author{
Martina Dyck ${ }^{1}$ and Mathias Lösche ${ }^{2,3},{ }^{*}$ \\ University of Leipzig, Institute of Experimental Physics I, D-04103 Leipzig, Germany, Carnegie \\ Mellon University, Department of Physics, Pittsburgh, PA 15213-3890, USA, and CNBT \\ Consortium, NIST Center for Neutron Research, Gaithersburg, MD 20899-8562, USA
}

\begin{abstract}
The association of neuropeptide Y (NPY) with air/water interfaces and with phospholipid monolayers on water subphases and on physiological buffer has been investigated. Surface pressure $(\pi) v s$. molecular area $(A)$ relations of the peptide at water surfaces depend on the concentration of the spreading solutions. Independent of that concentration, they show a transition from a low-density state to a high-density state at $\pi \sim 12 \mathrm{mN} / \mathrm{m}$. Similar features are observed in the NPY adsorption to preformed monolayers $\left(\Delta \pi(t \rightarrow \infty)\right.$ as a function of $\pi_{i}=\pi(t=0)$ where $t=0$ signifies the time of peptide injection). The transition is also observed in cospread lipid/NPY monolayers and is interpreted as the exclusion of the peptide from the surface layer. The reproducibility of the isotherms after expansion suggests that cospread lipid/peptide monolayers are thermodynamically stable and that the peptide remains associated with the monolayer after exclusion from the lipid surface.
\end{abstract}

A comparison of NPY association with zwitterionic and with anionic lipids, as well as a comparison of the interactions on pure water and on physiological buffer, suggests that electrostatic attraction plays a major role in the energetics of peptide binding to the membrane surface. Dual label fluorescence microscopy demonstrates that the peptide associates preferentially with the disordered liquid-condensed (LC) monolayer phase and also suggests that it self-aggregates upon exceeding a critical surface concentration. A NPY variant with a distorted $\alpha$-helix interacts with the surface as strongly as the natural NPY but expands the monolayers more. This suggests that the helix motif in the peptide is more important for the interaction with the receptor than for binding of the peptide to the membrane surface. In context, these observations attribute a specific role to the membrane in funneling the signal peptide to its membrane receptor.

\section{Introduction}

The interaction of peptides with cell membranes plays important roles in many biological processes, including cell signaling. As first quantitatively shown by Adam and Delbrück, ${ }^{1}$ the reduction of dimensionality affects the efficiency of ligand diffusion, thus increasing the probability for receptor binding substantially. This led to the speculation that - beyond their

*Corresponding Author. e-mail: quench@cmu.edu.

${ }^{1}$ University of Leipzig

${ }^{2}$ Carnegie Mellon University

${ }^{3}$ CNBT Consortium

SUPPORTING INFORMATION AVAILIBLE FT-IRRA spectra of a neat hNPY monolayer at the air-water interface, recorded at several surface pressures, indicate that the peptide is in an $\alpha$-helical conformation. This suggests strongly that spreading the peptide from organic solution does not affect its overall conformation in the monolayer film. This material is available free of charge via the Internet at http://pubs.acs.org. 
roles in, e.g., compartmentalization or the lateral organization of membrane protein complexes - internal cell membranes also facilitate short reaction times and economic use of low concentrations of signal molecules. In this work, we investigate the association of neuropeptide Y (NPY), a hormone and neurotransmitter that may be regarded a prototypical peptide ligand to transmembrane receptors, with membrane surfaces.

Neuropeptide $\mathrm{Y}$ is a tyrosine-rich, 36 amino acid (AA) neurotransmitter peptide, first isolated from porcine brain, ${ }^{2}$ but also found throughout the central and peripheral nervous system of many other mammalian species, including humans. ${ }^{3,4}$ It belongs to a family of endocrine peptides that includes peptide YY and pancreatic polypeptide (PP). Its membrane targets are the receptors $\mathrm{Y}_{1}-\mathrm{y}_{6}$, that belong to the rhodopsin-like superfamily of $\mathrm{G}$ protein coupled receptors. 5 NPY has been implicated in metabolic and cardiovascular regulation and is involved in the expression of other hormones. It has thus been extensively studied in pharmaceutical research.

Nuclear magnetic resonance (NMR) showed that the NPY structure incorporates an amphiphilic $\alpha$-helix, which extends from residue 13 to 36 and that its $\mathrm{N}$-terminus is disordered. 6 In solution, the peptide forms dimers, thus reducing the water contacts of the hydrophobic faces of the $\alpha$-helices. ${ }^{5}$ Both the parallel and anti-parallel orientations of the dimer are in equilibrium with a partially unfolded monomer. Studies on structure and dynamics of micellebound NPY $5,7-10$ indicated that the peptide is located at the lipid-water interface with its Nterminal helix parallel to the membrane surface; it penetrates the hydrophobic micelle core only via insertions of a few aliphatic or aromatic side-chains. These findings led to a three-step model of receptor selection: 5 The peptide binds to membranes as a monomer, thus shielding the hydrophobic face of its $\alpha$-helix; next, the membrane-bound NPY engages in a twodimensional (2D) diffusion process along the membrane surface, thus eventually finding and binding to its receptor.

As the important step of membrane binding appears to involve the lipid-water interface, Langmuir monolayers (LM) may provide the opportunity to obtain detailed information about this binding process. LMs have been intensively studied as well-defined model systems for biological membranes. ${ }^{11-14}$ Although resembling only one layer of the membrane, they are quite adequate to mimic biophysical processes at membrane surfaces such as peptide binding. 15 Here we use LMs to study thermodynamic aspects and the lateral organization of membraneassociated NPY on the $\mu \mathrm{m}$ scale. Investigations of the system using surface-sensitive IR spectroscopy (Fourier-transform infrared reflection adsorption spectroscopy, FT-IRRAS) will be reported in a forthcoming publication. ${ }^{16}$ Specifically, the role of NPY's amphiphilic $\alpha$-helix in the process of membrane binding is investigated by comparing native human NPY (hNPY) with a derivative, ${ }^{17}$ Y20P-NPY, in which the 'helix breaker' proline replaces a tyrosine at position 20 , in the center of the $\alpha$-helix motif.

In this paper, we first quantify the adsorption of NPY to spread monolayers from solution. We then show that monolayer isotherms of cospread lipid/NPY are comparable on saline solutions and on pure water. In what follows, we therefore characterize these systems further on saltfree aqueous subphases - to keep the system as simple as possible - and assess the association of NPY with aqueous surfaces and with lipid monolayers of zwitterionic and charged phospholipids on water subphases. While surface monolayers of pure NPY are metastable they show characteristic signatures that correlate with molecular dimensions and are thus indicative of molecular reorganization. These same features are also observed in mixed lipid/peptide monolayers which in turn are fully reversible in their compression/expansion behavior, and are thus likely close to their thermodynamically stable state. This is demonstrated by measuring Langmuir isotherms as a function of peptide concentration in the mixed surface layers. We 
complete this study by assessing the lateral distribution of fluorescently labeled peptide and lipid to characterize the molecular association on the $\mu \mathrm{m}$ length scale.

\section{Materials and Methods}

\section{A. Materials}

Human neuropeptide $Y$ (one-letter code sequence: YPSKP DNPGE DAPAE DMARY YSALR HYINL ITRQR Y-NH ${ }_{2}$ ) and Y20P-NPY, as well as carboxyfluorescein (CF)-labeled hNPY were generous gifts from A. G. Beck-Sickinger (Leipzig). 1,2-dipalmitoyl-sn-3glycerophosphocholine (DPPC, Sigma-Aldrich, Deisenhofen, Germany) and 1,2-dimyristoyl$s n$-3-glycerophosphoserine (DMPS, Avanti Polar Lipids, Alabaster, AL) were used as supplied. The fluorescent labels, 1-difluorodiphenylboradiazaindacene-2dodecanoylhexadecanoyl-sn-3-glycerophosphocholine (BODIPY-HPC) and 1,2-dihexadecanoyl-sn-3-glycerophosphoethanolamine-lissamine rhodamine B (L-rhod B-DHPE) were from Molecular Probes (Leiden, Netherlands). Ultrapure water, used for the preparation of subphases in the home-built Langmuir film balance, was filtered in a Millipore Milli-Q system, yielding a residual specific resistance of $\sim 18.2 \mathrm{M} \Omega \mathrm{cm}$. HPLC grade chloroform and methanol (Merck, Darmstadt, Germany) were used as spreading solvents. HEPES, sodium hydroxide and sodium chloride were from Sigma-Aldrich.

\section{B. Methods}

Isotherms and fluorescence microscopy-Surface layers were spread on the subphase from either lipid, peptide or premixed lipid/peptide solutions in chloroform/methanol (3:1). The solvent was allowed to evaporate for at least $10 \mathrm{~min}$. The home-built, thermostated Teflon (PTFE) Langmuir film balance used for the measurement of surface isotherms has a maximum area of $100 \times 300 \mathrm{~mm}^{2}$ and a compression ratio (maximum : minimum area) of $\sim 4: 1$. The surface pressure, $\pi$, is continuously monitored using ash-free filter paper as Wilhelmy plate. Unless otherwise stated, isotherms were recorded at $20^{\circ} \mathrm{C}$, and the monolayers were typically compressed at a barrier speed that corresponded to $1.8 \AA^{2} /($ molecule $\times$ min). The Zeiss Axiotech Vario fluorescence microscope and associated film balance have been previously described. ${ }^{18}$

Peptide adsorption to lipid monolayers-Adsorption experiments were performed on a home-built, thermo-controlled circular PTFE trough. It is miniaturized for economic use of adsorbents, equipped with a Wilhelmy plate (but no means to adjust the surface area) and fitted with a magnetic stirrer and a vertical tube for peptide injection. Its surface area is $7.1 \mathrm{~cm}^{2}$ and its subphase volume is $11.15 \mathrm{~mL}$. Lipid monolayers were spread to a specific pressure from solutions. After equilibration, hNPY in buffer $(20 \mu \mathrm{L}$ of a $0.1 \mathrm{mM}$ solution in $10 \mathrm{mM}$ HEPES, $\mathrm{pH} 7.4,150 \mathrm{mM} \mathrm{NaCl}$ ) was injected underneath the surface monolayer to yield a subphase concentration of $\sim 0.17 \mu \mathrm{mol} / \mathrm{L}$, and the surface pressure response recorded.

\section{Results}

\section{Layout of experiments}

Most experiments were carried out on both pure water subphases and physiological buffer (10 $\mathrm{mM}$ HEPES, pH 7.4, $150 \mathrm{mM} \mathrm{NaCl})$. Pressure-area $(\pi-A)$ relations for pure peptides and isotherms of cospread DPPC/peptide monolayers recorded on water and on buffer were largely identical. This is a consequence of the fact that electrostatic (Debye-Hückel) screening plays a minor role for dipole-dipole interactions. For purely zwitterionic lipid monolayers, one may thus investigate the association of peptide with the lipid surface in simple aqueous systems. This is attractive, since the molecular-scale interpretation of, e.g., IR or surface-sensitive scattering is simpler for nonionic subphases. Similar studies of peptide association with 
charged lipid surfaces (using DMPS as an anionic lipid) both on ionic and ion-free subphases were performed to quantify the role of screening in peptide-lipid interactions. External Fourier transform infrared reflection-adsorption spectra (FT-IRRAS) of neat peptide surface layers and mixed lipid/peptide monolayers at the air-water interface showed that the peptide retains its predominantly $\alpha$-helical structure at the interface under the experimental conditions described above. A set of such spectra at various surface pressures are provided as supporting information. A more detailed account of the FT-IRRAS study of NPY association at surfaces and with lipid monolayers is described elsewhere. ${ }^{16}$

\section{Surface films of neat peptide}

Figure 1 shows a helix wheel representation of hNPY between D16 and R33, a region in which the $\alpha$-helix is best defined. ${ }^{5}$ Clearly, an angular separation is observed between hydrophobic residues (black) and hydrophilic residues (white) that leads to a pronounced hydrophobic moment (arrow in the wheel center). The schematic shows how M17, L24, I28, and I31 line one face of the helix hydrophobically. $\pi$ - $A$ relations of films spread from peptide solutions of both hNPY and Y20P-NPY are also displayed in Fig. 1. Both peptides show significant surface activity and associate with the air/water interface if spread from organic solvent.

Generally, the surface pressure rises exceedingly slowly upon compression, so that the full $\pi$ $A$ relation cannot be recorded in one single experiment on a film balance with a compression ratio of $4: 1$. Moreover, the surface films are metastable in that $A$ at a given $\pi$ depends to some extent - smaller than a factor of 2 - on the concentration of the spreading solution: more dilute solutions produce apparently more expanded peptide monolayers. On the other hand, the shape of the $\pi-A$ curve is independent of the amount spread. Therefore this relation may be recorded over the entire range of interest by spreading increasing amounts of peptide in a series of experiments and subsequently combining the partial 'isotherms'. Figure 1 shows such composite $\pi-A$ plots. The values of $A$ relate to peptide concentrations in the spreading solution of $0.4 \mathrm{~g} / \mathrm{ml}$ and are presented to relate tentative molecular organizations to approximate molecular dimensions. The $\pi$ - $A$ plot of hNPY shows a transition from a state of lower compressibility to a region of higher compressibility at $\pi \sim 12 \mathrm{mN} / \mathrm{m}$. Similar features have been reported in other peptide systems where they have been identified as the collapse of a well-defined surface layer of $\alpha$-helices at a pressure, $\pi_{c o l} .19,20 \mathrm{IR}$ results on NPY surface films, to be discussed in a separate publication, ${ }^{16}$ confirm this view. The isotherms of surface layers deposited from mixed lipid/NPY solutions show compressibility increases similar to those in neat peptide monolayers, although at elevated pressures (see below). Above $\pi \sim 20 \mathrm{mN} / \mathrm{m}$, the surface-associated layer becomes unstable and peptide is presumably expelled into the subphase.

It is evident that $\mathrm{Y} 20 \mathrm{P}-\mathrm{NPY}$ occupies significantly more area within a surface layer than $\mathrm{hNPY}$ at comparable pressures. Apparently, distortion of the hNPY $\alpha$-helix by P20 leads to a more disordered molecular organization in which the peptide density in the surface film is reduced. The Y20P-NPY isotherm shows also an inflection point, which is, however, less developed and occurs at a lower surface pressure than with hNPY. Nevertheless, as the $\pi-A$ demonstrates, is the surface activity of Y20P-NPY similar to that of hNPY.

The area occupation of the peptide in the surface films along the $\pi-A$ curve is consistent with the notion that the helix axis aligned with the interface at low $\pi(<12 \mathrm{mN} / \mathrm{m})$. By the same argument, it appears that helices are expelled from the water surface at high $\pi$. Presumably, they self-associate into aggregates that shield their hydrophobic faces mutually from exposure to the solvent. 


\section{NPY adsorption to preformed lipid monolayers}

To investigate the interaction between hNPY in bulk solution and lipid surface films, lipid monolayers were prepared at different surface pressures and hNPY injected into the subphases. Figure 2 shows the surface pressure increase, $\Delta \pi(t \rightarrow \infty)$, as a function of the initial pressure $\pi_{i}$. Independent of the salinity of the subphase, hNPY interacts with zwitterionic and anionic monolayers rapidly, as indicated by the instantaneous increase in surface pressure. On the other hand, $\Delta \pi$ depends on the intensity of electrostatic interactions, as suggested from the results in Fig. 2 where DPPC shows the smallest and DMPS on $\mathrm{H}_{2} \mathrm{O}$ shows the largest effect. Moreover, when compared to water subphases the interaction between peptide and anionic lipid surfaces is strongly reduced on physiological buffer such that at high $\pi$ there are no significant differences between NPY association with zwitterionic lipids $\left(\mathrm{on}_{2} \mathrm{O}\right)$ and with anionic lipids on buffer subphase. In addition, a reduction of charges on the peptide may favor incorporation into the surface monolayer, since $\mathrm{pH} 7.4$ is close to the isoelectric point of NPY. The dependence of $\Delta \pi$ on $\pi_{i}$ indicates for all three systems a significant reduction of peptide-lipid interaction at $\pi_{i} \sim 15 \mathrm{mN} / \mathrm{m}$. At larger $\pi_{i}, \Delta \pi$ drops linearly with $\pi_{i}$ and vanishes at $\sim 40 \mathrm{mN} /$ $\mathrm{m}$. Due to the difficulties in controlling $\pi_{i}$ precisely on the available equipment it was not possible to map this relation out in more detail.

\section{Peptide/DPPC monolayer isotherms}

In contrast to the metastable character of peptide surface films, apparent from the dependence of the film area on the concentration of the spreading solution, co-spread phospholipid/peptide monolayers are thermodynamically stable. They are dominated by the thermodynamic characteristics of the lipid component for peptide concentrations up to $8 \mathrm{~mol} \%$, investigated in this study. We have characterized the association of hNPY and Y20P-NPY with the zwitterionic phospholipid, DPPC, and with anionic DMPS on pure $\mathrm{H}_{2} \mathrm{O}$ (at $\mathrm{pH} \sim 6$, the acidity of ultrapure water under ambient air that contains $\left.\mathrm{CO}_{2}\right)$ and on physiological buffer $(10 \mathrm{mM}$ HEPES, $\mathrm{pH} 7.4,150 \mathrm{mM} \mathrm{NaCl}$ ). These lipids were selected since they both exhibit a first-order phase transition (liquid expanded/liquid condensed, LE/LC) in their monolayers at $20^{\circ} \mathrm{C}-\mathrm{a}$ feature which is useful for the investigation of molecular-scale interactions between the film components. 21

Figure 3 shows $\pi$ - $A$ isotherms of DPPC at $20^{\circ} \mathrm{C}$, cospread with various concentrations of hNPY (Fig. 3a) and Y20P-NPY (Fig. 3b). We represent $A$ as the area per lipid molecule, independent of the peptide content of the spreading solution, because it cannot be assumed a priori that all the cospread peptide molecules remain associated with the surface. Furthermore, it is unclear whether the peptide incorporates into the lipid monolayer or adsorbs to its headgroup layer. Finally, the characteristic size of the peptide - or its helical segment - is much larger than that of a phospholipid, so that such a representation appears appropriate.

The isotherm of the neat DPPC monolayer is consistent with literature data. ${ }^{21}$ Increasing hNPY concentrations expand the isotherm monotonically. The onset pressure of the lipid LE/LC transition, $\pi_{c}$, increases only slightly with $c_{N P Y}$, both for hNPY and Y20P-NPY. Another prominent feature in these isotherms, an inflection that precedes a subsequent sloped plateau, is observed at $\sim 14 \mathrm{mN} / \mathrm{m}$ for DPPC/hNPY (Fig. 3a). It occurs at about the same pressure, $\pi_{c o l}$, where the peptide layer collapse is observed for neat hNPY (Fig. 1) and is more pronounced at higher hNPY concentrations. It is, however, already visible at $c_{N P Y}$ as low as 1 mol\% and is virtually independent of $c_{N P Y}$.

Y20P-NPY containing surface layers show similar characteristics as those that contain hNPY - an expansion of the isotherm with at best a slight increase of $\pi_{c}$ - and features at higher $\pi$ that are attributed to the peptide. As in the $\pi$ - $A$ plot characteristic of neat peptide monolayers, these features are ill defined in comparison to hNPY. 


\section{Peptide/DMPS monolayer isotherms on $\mathrm{H}_{2} \mathrm{O}$}

As shown in the peptide adsorption experiments (Fig. 2) and expected from the high density of dipolar residues on NPY, the peptide interacts with anionic monolayers more intensively than with zwitterionic monolayers. Figure 4 shows $\pi-A$ isotherms of co-spread DMPS and NPY at $20^{\circ} \mathrm{C}$. Both hNPY (Fig. 4a) and Y20P-NPY (Fig. 4b) expand the neat DMPS monolayer at comparable values of $c_{N P Y}$ more than DPPC. In particular with hNPY, $\pi_{c}$ increases significantly with $c_{N P Y}$ until the phase transition virtually disappears at $\sim 6 \mathrm{~mol} \%$ peptide. The collapse pressure of hNPY is shifted to $\pi_{c o l}>22 \mathrm{mN} / \mathrm{m}$, indicating significantly stronger molecular interactions between the lipid and the peptide.

\section{Peptide/DMPS monolayer isotherms on buffer}

Sodium ions in physiological buffer screen the charge on anionic monolayers. Bilayer experiments have shown that monovalent cations decrease the lipid phase transition temperature, ${ }^{22}$ which is also true for monolayers as observed in Fig. 5. The plateau of the DMPS isotherm is shifted to higher surface pressures with increasing ion concentration. This may be interpreted as an inclusion of sodium ions in the head group region. ${ }^{23}$

Since NPY has its isoelectric point at $\mathrm{pH}$ 7.4, weaker electrostatic interactions and therefore lesser expansion of the DMPS monolayer on buffer than on water are predicted. Figure 6 shows $\pi-A$ isotherms which validate this expectation. The ionic subphase shifts the lipid phase transition to $\pi \sim 17 \mathrm{mN} / \mathrm{m}$ where it overlaps with the peptide-associated plateau. It is possible to separate the two plateaus by decreasing the temperature of the subphase, since the LE/LC phase transition of DMPS then shifts to lower surface pressures (Figure 7) whereas the peptideassociated plateau is largely temperature insensitive.

\section{Surface pressure hysteresis}

As shown in Figure 8, mixed monolayers of NPY with both DPPC and DMPS show only minor hystereses when the compressed films are expanded and recompressed. Monolayers were allowed to relax for $\sim 1$ hour before recompression was started. With DMPS on $\mathrm{H}_{2} \mathrm{O}$ subphase (Fig. 8b), a hysteresis is virtually absent. For DPPC on $\mathrm{H}_{2} \mathrm{O}$ and DMPS on buffered subphase (with $4 \mathrm{~mol} \% \mathrm{hNPY}$ ), the reinsertion is more incomplete during the 1 hour wait period.

Nevertheless, the subsequent recompression isotherm displays all features of the isotherm recorded during the initial compression, and in particular above $\pi_{c o l}$ of hNPY the second compression isotherm retraces the first almost perfectly. The apparent reinsertion of peptide indicates that material which may have been expelled from the monolayer upon compression remains surface-associated and is therefore not irreversibly lost to the bulk subphase.

\section{Work of compression}

Since DPPC and DMPS isotherms of are similar in shape, indicating a similar balance of attractive and repulsive interactions between the lipid molecules for the two species, it might be expected that the adsorption or incorporation of NPY should induce similar changes. Obviously this is not the case, as the peptide's collapse pressure, $\pi_{c o l}$, is shifted to higher $\pi$ in DMPS monolayers on water. This indicates again that the affinity between DMPS and NPY is strongly enhanced by electrostatic interactions. The work of compression, $W_{c}$, can be used as a measure for monolayer stability and is estimated from the isotherm as ${ }^{19}$

$$
W_{c}=\int_{\text {initial }}^{\text {final }} \pi \mathrm{d} A
$$

Figure 9 shows $W_{c}$, normalized to $W_{c}{ }^{L}$ of the pure lipid, as a function of $c_{N P Y}$. As already suggested from the isotherms, the DMPS/peptide monolayers on water are most stable, while DPPC/peptide monolayers are least stable. The stability of mixed DMPS/hNPY monolayers on buffer is similar to those of zwitterionic lipids. 


\section{Fluorescence microscopy}

Optical microscopy is a sensitive means of assessing the lateral $\mu \mathrm{m}$-scale organization of phaseseparated surface monolayers, e.g., in the course of structural phase transitions. ${ }^{21}$ The shape of domains that are formed during a first-order phase transition are in fact the most sensitive indicator of molecular additives whose interaction with the membrane surface changes their morphology. ${ }^{21,24}$ Traces of hydrophobic pollutants that are too dilute for a quantitative assessment may alter the morphogenesis in these monolayer phase transitions significantly. Moreover, a detailed analysis of such shapes can be utilized to quantify molecular interactions between the monolayer constituents. $21,25,26$

To assess NPY association with phospholipid membrane surfaces, we started with dual-label experiments in which L-rhod B-DHPE ( $\sim 0.4 \mathrm{~mol} \%$ with respect to total lipid) was used to label the lipid monolayer while CF-hNPY ( $10 \mathrm{~mol} \%$ with respect to total peptide) was used to visualize the peptide distribution at the surface. Since the absorption and emission spectra of these two labels are sufficiently separated, this enables a discrimination of the different labels using appropriate filter sets. Such experiments therefore assess with which of the coexisting lipid phases in a phase-separated lipid monolayer the peptide associates preferentially (the lipid label has been shown to partition preferentially into the more disordered, fluid LE phase). Figure 10 shows a comparison of the distinct label distributions in a surface layer of DPPC with $8 \mathrm{~mol} \%$ hNPY. Two images recorded with different filter sets show the same area (white circles mark the same surface feature) in the monolayer. It is evident that the CF-hNPY decorates the same areas which the L-rhod B-DHPE probe reveals as regions of fluid lipid.

Figure 11 presents a set of fluorescence images ( $0.4 \mathrm{~mol} \%$ BODIPY-HPC in all experiments) at different lipid/peptide compositions and different surface pressures as indicated. The upper left shows an image characteristic of a neat DPPC monolayer toward the end of the LE/LC phase transition. ${ }^{27}$ At higher $\pi$, the phase transition is terminated although remnants of the previously fluid phase that contain the labeled lipid in high concentration remain visible. As has been shown before, the redistribution of these highly concentrated labels within the monolayer proceeds only slowly due to the low diffusivity within the LC phase. ${ }^{28}$

At $2 \mathrm{~mol} \% \mathrm{hNPY}$ in DPPC, the domain shapes are visually distorted, although their general features are conserved. In particular at low $\pi(10 \mathrm{mN} / \mathrm{m})$, the peptide stabilizes the fluid phase, a trend that becomes very pronounced at higher $c_{N P Y}(5 \mathrm{~mol} \%$ and $8 \mathrm{~mol} \%)$. At $c_{N P Y}>4 \mathrm{~mol}$ $\%$ compression induces the formation of small (apparent diameters, $1-2 \mu \mathrm{m}$ ) inhomogeneities that form within the dye-enriched lipid phase (e.g., Fig. 11:5 mol\% hNPY at $15 \mathrm{mN} / \mathrm{m}$ ). Once formed, these small heterogeneities persist up to high $\pi$; their first appearance is observed at progressively lower $\pi$ as the peptide concentration is increased. This hints at the formation of peptide aggregates as the local NPY concentration surpasses a solubility threshold.

The admixture of Y20P-NPY with DPPC induces similar effects on the monolayer phase morphology as does hNPY, although these effects - a stabilization of the fluid phase and NPY self-aggregation at high compression - are less pronounced (data not shown). Finally, consistent with the stronger expansion of DMPS monolayer isotherms by NPY as compared with that of DPPC, the fluid lipid phase stabilization in DMPS by NPY is even more pronounced than with the zwitterionic lipid. A representative pair of fluorescence micrographs without peptide and with $2 \mathrm{~mol} \% \mathrm{hNPY}$ at $4 \mathrm{mN} / \mathrm{m}$ - where the phase transition is virtually completed in neat DMPS - is shown in Fig. 12. The neat phospholipid monolayer is almost completely condensed (with remaining fluorescence label squeezed into regions that account for less than $2 \%$ of the total surface area). In contrast, the fluorescent regions in the surface film that contains 2 mol\% hNPY occupy $>50 \%$ of the total surface area. Obviously, the peptide stabilizes the anionic lipid in the fluid phase state to a great extent. Again, at higher $\pi$ the 
formation of small inhomogeneities in the fluid phase is observed. Similarly evident is the fluid phase stabilization at higher $\pi$ (not shown).

\section{Discussion}

From the amphipathic character of the peptide, its substantial solubility in aqueous buffer and previous studies of micelle-bound NPY 5 it appears unlikely that NPY incorporates into the hydrophobic core of the membrane. If the peptide, on the other hand, preferentially associates with the hydrophilic, and chemically 'promiscuous', ${ }^{29}$ membrane surface, lipid monolayers are an appropriate tool to study such interaction. The most basic results - such as the isotherms in Figs. 3 and 4 - have already validated this approach. If the interaction of the peptide with the membrane surface was marginal, one would expect only a small impact on the isotherms. The same would be true if the peptide interacted strongly with the hydrophobic interior of the membrane. In that case, one expects that in a monolayer model the peptide would be squeezed out of the alkane phase towards the gas phase upon compression.

Cospreading of lipids and peptides from organic solution has been shown to be a valid approach to form biomimetic peptide/lipid surface layer systems $18,30-33$ provided that the peptide doesn't denature in the organic phase. After solvent evaporation, the peptide/lipid surface films may form a thermodynamically well-defined system. This is the case here, as demonstrated by the reproducibility and stability of the resulting surface films, and the reinsertion of the peptide into the monolayer after expansion. To obtain a better understanding of the roles of electrostatic interactions and of NPY's secondary structure for membrane interaction, experiments with zwitterionic lipids and with charged lipids were carried out, and a proline-substitution on the peptide that interferes with its ability for receptor binding 17 was also investigated.

The hydrophobicity $H$ of a peptide is determined by the free energy penalty for the collective transfer of its constituent AAs from a hydrophobic to a hydrophilic environment, i.e.

$H=\sum_{i} h_{i}$. Beyond this energetic consideration, the hydrophobic moment $\vec{\mu}_{H}$ is a quantitative measure of the amphipathicity of a peptide. It is defined as the vector sum of hydrophobic moments $\vec{e} h$ as 34,35

$$
\bar{\mu}_{H}=\sum_{i} \bar{e}_{i} h_{i}
$$

where $\vec{e}$ is a unit vector pointing from the $\alpha$ carbon of the $i$-th AA to the center of its side chain. The $\alpha$-helical segment, hNPY(13-36) has a fairly large hydrophobic moment,

$\vec{\mu}_{H} \mid=0.299$ per AA on Eisenberg's 'consensus scale' 34 (in which $h$ may be approximately interpreted as the transfer energy in $\mathrm{kcal} / \mathrm{mol}$ ). On the same scale, the membrane-lytic peptides mellitin(1-21) and magainin obtain scores of 0.266 and 0.286 per AA, respectively. The model peptide KLAL, ${ }^{36}$ optimized for its large hydrophobic moment, amounts to 0.334 per AA.

NPY is associated with the surface up to significant surface pressure $(\pi \sim 12 \mathrm{mN} / \mathrm{m}$ in Fig. 1 , see also Figs. 3 , 4). In conjunction with its large hydrophobic moment, $\mu_{H} \sim 7.2$ on Eisenberg's scale, ${ }^{34}$ this suggests that the helix is coplanar with the water surface below the transition pressure. Estimates of the peptide's surface cross-section computed from the length of the helix motif are consistent with this assumption. For a well-ordered $\alpha$-helical segment of 24 AAs one expects a footprint of $10 \AA \times 24 \mathrm{AA} \times 1.5 \AA$ (per AA) $\sim 360 \AA^{2}$. A well-defined inflection point in the $\pi-A$ curve at $\sim 12 \mathrm{mN} / \mathrm{m}$ is evident for neat NPY surface layers and is preserved in mixed lipid/hNPY monolayers, where it occurs at $\pi \sim 14 \mathrm{mN} / \mathrm{m}$ in DPPC monolayers, and at substantially larger $\pi$ in DMPS monolayers. The influence of surface-associated peptides on surface isotherms is largely determined by their secondary structure. The observed plateau is a characteristic feature of $\alpha$-helical peptides and is interpreted in terms of a collapse of the helix 
layer at a characteristic surface pressure, $\pi_{c o l} \cdot 19,20$ Therefore, $\pi_{c o l}$ is a measure of the peptide's contribution to film stability. Peptide detachment from the surface above $\pi_{c o l}$ is reversible (Fig. 8 ) which suggests that the peptide remains associated with the monolayer, presumably in the form of dimers or larger aggregates. Clustering of NPY along or close to the cell membrane has been observed by Bettio and coworkers. ${ }^{37}$

Peptide interactions with membranes are much more complex than their interaction with water surfaces. The chemically promiscuous lipid headgroup region may act as a partner that engages in hydrophobic, electrostatic, hydrogen bonding and van-der-Waals interactions with surfaceassociated peptides. Mixed lipid/NPY monolayer isotherms show a monotonic increase of their surface area with peptide concentration. In particular hNPY at zwitterionic DPPC surfaces shows a collapse signature very similar to that of neat peptide surface layers (Figs. 1, 3) at virtually the same $\pi$ value. This indicates that van-der-Waals interactions do not play a prominent role in the peptide association with the membrane surface. With anionic membrane surfaces (DMPS, c.f. Fig. 4a) a similar feature is observed, although at significantly increased $\pi(>22 \mathrm{mN} / \mathrm{m})$. Since NPY carries a net charge of $+1 \ldots+2$ in the $\mathrm{pH}$ range between 6 and 7 , this suggests stabilization of peptide/lipid interactions by electrostatic contributions. With an isoelectric point at $\mathrm{pH}$ 7.4, the electrostatic interactions between DMPS and NPY are weaker on buffer than on pure water subphase. The adsorption experiments support this interpretation of the isotherms: Electrostatic interactions between the positively charged NPY and the anionic DMPS lead to a strong lipid-peptide association.

Lipid/Y20P-NPY surface layers show characteristics similar to lipid/hNPY. While it may be an important factor for receptor binding, we infer that the secondary structure, specifically the $\alpha$-helix, does not significantly affect the membrane association of the peptide. Differences between the two systems include a more pronounced monolayer expansion of Y20P-NPY as well as the lack of a distinctive signature of collective peptide expulsion from the interface as observed in the hNPY/lipid systems.

In contrast to neat peptide monolayers, the isotherms of the mixed systems are stable comparable to the stability of neat phospholipid monolayers - and show only moderate hysteresis upon expansion and recompression (Fig. 8). Surface layers retain features that are characteristic of neat lipid monolayers; in addition, characteristic features appear that scale with NPY concentration. Lipid/peptide monolayers are stable well beyond the collapse point of neat peptide surface layers $(\sim 20 \mathrm{mN} / \mathrm{m})$. Their stability is comparable with that of neat lipid monolayers (collapse point above $50 \mathrm{mN} / \mathrm{m}$ ) in most cases.

Fluorescence microscopy shows that NPY partitions preferentially onto the fluid lipid phase, thereby increasing the relative amount of this phase. For other small amphiphilic adsorbents such as local anesthetics, viral or antibiotic peptides, this is accompanied with an increase in membrane disorder. ${ }^{38}$ The peptide impact on the lipid is apparently very prominent in DMPS/ peptide monolayers. The domain shapes are distorted while their general features are conserved.

At $c_{N P Y}>4 \mathrm{~mol} \%$ in a DPPC matrix and $c_{N P Y}>2 \mathrm{~mol} \%$ in a DMPS matrix, the reduction of monolayer area upon compression induces the formation of surface-associated, non-

fluorescent particles. We attribute these to peptide aggregates or lipid-peptide aggregates, in which water exclusion between hydrophobic faces of adjacent $\alpha$-helices is the dominant interaction. ${ }^{39}$ Such granular structures were also observed in experiments with CF-NPY and unlabeled lipid. Here, the fluorescently labeled peptide may be invisible within the grains due to self-quenching of the CF label. While Y20P-NPY induces similar effects on the lipid phase morphology as hNPY, a formation of granular structures is not observed. This corrobates the 
interpretation that the grains consist of peptide aggregates, as the disruption of the $\alpha$-helix at Tyr20 may greatly reduce the propensity of the peptide for self-aggregation.

Altogether, the experimental results suggest the following scenario. At low surface pressure NPY is associated with the lipid monolayer, presumably with its long helix axis preferentially parallel to the interface. The plateau at $\pi \sim 14 \mathrm{mN} / \mathrm{m}$ (DPPC/hNPY) or at $\pi \sim 22 \mathrm{mN} / \mathrm{m}$ (DMPS/ $\mathrm{hNPY}$ ) indicates an exclusion of the peptide from the lipid headgroup region into the subphase where it, however, still remains peripherally associated with the membrane.

It has been argued that lipid bilayers are in a physical state that corresponds to that of a monolayer at surface pressures in the vicinity of $\pi \sim 30 \mathrm{mN} / \mathrm{m} .{ }^{40,41}$ If target membranes in vivo were only zwitterionic, this implies that NPY organization at the membrane surface would resemble that in a monolayer above $\pi_{c o l}$. However, biological membrane surfaces carry net negative charge and most membranes consist of complex mixtures of lipids, both charged and zwitterionic. As we show, NPY interacts particularly strongly with anionic lipids, and this may induce sorting of lipids in-plane such that anionic lipids would be sequestered to the surfacebound peptide. 42 The results for charged monolayers presented in Fig. 4 then suggest that the local interaction may induce a state in which the peptide is in the transition regime between loosely associated with the surface and embedded within the lipid headgroups. Under physiological conditions, the peptide may thus be is a state of membrane association from where it may easily detach or conversely insert more deeply depending on local fluctuations of physical parameters in its immediate environment. The absence of a hysteresis between the first and a second compression of the DMPS/NPY surface monolayer (Fig. 8b) stresses this aspect of a self-stabilizing system at the interface. We thus conclude that one important role of the membrane in NPY signaling is indeed to funnel the peptide to its receptor in a 2D rather than a 3D random walk. But even beyond, our findings here also suggest that local variations of environmental parameters, such as lipid composition, which might lead to tighter binding or expulsion from the surface, may be essential to direct the ligand to its receptor.

\section{Conclusions}

The association of NPY with water surfaces and lipid monolayers floating on water and physiological buffer was studied with the aim of establishing the molecular determinants of the interaction of the peptide with lipid membrane surfaces. The work reported here helps setting the scene for investigations with more quantitative characterization tools, such as infrared spectroscopy and surface-sensitive scattering, and seeks to establish sample preparation protocols for those experiments. We demonstrated that the peptide adsorbs readily to preformed lipid monolayers where it encounters an insertion barrier upon raising the initial monolayer pressure to above $\sim 15 \mathrm{mN} / \mathrm{m}$.

For spread peptide or peptide/lipid monolayers on aqueous surfaces we reported that (a) the lipid monolayer phase transition is well preserved when NPY is in contact with the membrane, (b) the peptide undergoes a transition from a membrane-bound state to a state in which it is excluded from the membrane but remains associated with it, so that (c) the peptide/lipid isotherms are largely reproducible upon expansion and recompression. This latter transition occurs at elevated pressure for DMPS host monolayers as compared to either pure peptide surface layers or to DPPC hosts. We attribute these energetic differences to electrostatic interactions between the peptide and anionic lipids. The lateral distribution of the peptide within the surface layer resembles that of the disordered lipid phase, LE, and is otherwise homogeneous up to a certain surface density, at which it self-aggregates into $\mu \mathrm{m}$ particles. Y20P-NPY shows patterns of surface association grossly similar to those of hNPY but requires more space within the monolayer and interacts even stronger with charged monolayers than the parent peptide. 
We conclude that the peptide in its physiological environment interacts preferentially with disordered membrane areas where it is presumably headgroup-associated with its $\alpha$-helix parallel to the interface. The disordered C-terminal stretch is rather hydrophilic and is thus not expected to interact strongly with the membrane. Anionic lipids enhance the association through electrostatic interactions. In a highly diverse lipidic alloy, the adsorbed peptide might preferentially sequester anionic lipids to its footprint on the membrane. If one accepts the view that the peptide utilizes the fluid bilayer as a vehicle to find its receptor more efficiently than through 3D diffusion in the bulk, one might envision a change in membrane association upon binding to the receptor if the receptor itself recruited ordered lipid patches in its vicinity, thus forming a membrane raft. The membrane-associated signal peptide would then come off the membrane as it enters the more ordered periphery of a receptor raft and gain kinetic flexibility for receptor binding.

Another important conclusion is that peptide/lipid surface monolayers prepared by cospreading are suitable systems for the investigation of membrane ligand interactions. In forthcoming publications, we will with surface analytical tools further investigate the molecular aspects of peptide-lipid interaction involving the NPY signal peptide.

\section{Supplementary Material}

Refer to Web version on PubMed Central for supplementary material.

\section{ACKNOWLEDGMENTS}

We thank A. G. Beck-Sickinger for the peptides and A. Kerth for help with the equipment for the peptide adsorption measurements. This work was supported by the NSF (grant no. 0555201), the Volkswagen Foundation (I/77709), the National Institutes of Health (1RO1 RR14812) and The Regents of the University of California.

\section{REFERENCES}

1. Adam, G.; Delbrück, M. Reduction of dimensionality in biological diffusion processes.. In: Rich, A.; Davidson, N., editors. Structural Chemistry and Molecular Biology. W.H. Freeman; New York: 1968. p. 198

2. Tatemoto K, Carlquist M, Mutt V. Nature 1982;296:659. [PubMed: 6896083]

3. Adrian TE, Allen JM, Bloom SR, Ghatei MA, Rossor MN, Roberts GW, Crow TJ, Tatemoto K, Polak JM. Nature 1983;306:584. [PubMed: 6358901]

4. Allen JM, Bloom SR. Neurochem. Int 1986;8:1.

5. Bader R, Bettio A, Beck-Sickinger AG, Zerbe O. J. Mol. Biol 2001;305:307. [PubMed: 11124908]

6. Monks SA, Karagianis G, Howlett GJ, Norton RS. J. Biomol. NMR 1996;8:379. [PubMed: 9008359]

7. Bettio A, Dinger MC, Beck-Sickinger AG. Protein Sci 2002;11:1834. [PubMed: 12070335]

8. Bettio A, Gutewort V, Pöppl A, Dinger MC, Zschörnig O, Arnold K, Toniolo C, Beck-Sickinger AG. J. Peptide Sci 2002;8:671. [PubMed: 12523644]

9. Lerch M, Mayrhofer M, Zerbe O. J. Mol. Biol 2004;339:1153. [PubMed: 15178255]

10. Thomas L, Scheidt HA, Bettio A, Huster D, Beck-Sickinger AG, Arnold K, Zschörnig O. Biochim. Biophys. Acta 2005;1714:103. [PubMed: 16095559]

11. Möhwald H. Annu. Rev. Phys. Chem 1990;41:441. [PubMed: 2257038]

12. Möhwald H, Baltes H, Schwendler M, Helm CA, Brezesinski G, Haas H. Jpn. J. Appl. Phys 1995;34:3906.

13. McConnell HM. Annu. Rev. Phys. Chem 1991;42:171.

14. Knobler CM, Desai RC. Annu. Rev. Phys. Chem 1992;43:207.

15. Brockman H. Current Opin. Struct. Biol 1999;9:438.

16. Dyck M, Kerth A, Blume A, Lösche M. J. Phys. Chem. B. 2006submitted 
17. Fuhlendorff J, Johansen NL, Melberg SG, Thogersen H, Schwartz TW. J. Biol. Chem 1990;265:11706. [PubMed: 2164012]

18. Krüger P, Schalke M, Wang Z, Notter RH, Dluhy RA, Lösche M. Biophys. J 1999;77:903. [PubMed: 10423435]

19. Birdi, K. Lipid and Biopolymer Monolayers at Liquid Interfaces. Plenum Press; New York: 1989.

20. Maget-Dana R. Biochim. Biophys. Acta 1999;1462:109. [PubMed: 10590305]

21. Krüger P, Lösche M. Phys. Rev. E 2000;62:7031.

22. Träuble H, Eibl H. Proc. Natl. Acad. Sci. USA 1974;71:214. [PubMed: 4521052]

23. Helm CA, Laxhuber LA, Lösche M, Möhwald H. J. Colloid Polym. Sci 1986;264:46.

24. McConlogue CW, Vanderlick TK. Langmuir 1999;15:234.

25. McConnell HM, Moy VT. J. Phys. Chem 1988;92:4520.

26. Fischer, TM.; Lösche, M. Pattern formation in Langmuir monolayers due to long range electrostatic interactions.. In: Michel, D.; Haberlandt, R.; Pöppl, A.; Stannarius, R., editors. Lecture Notes in Physics. 634. Springer; New York: 2004. p. 383

27. McConlogue CW, Vanderlick TK. Langmuir 1997;13:7158.

28. Lösche M, Sackmann E, Möhwald H. Ber. Bunsenges. Phys. Chem 1983;87:848.

29. White SH, Wimley WC. Annu. Rev. Biomol. Struct 1999;28:319.

30. Krüger P, Baatz JE, Dluhy RA, Lösche M. Biophys. Chem 2002;99:209. [PubMed: 12408937]

31. Trommeshauser D, Krol S, Bergelson LD, Galla H-J. Chem. Phys. Lipids 2000;107:83. [PubMed: 10974232]

32. Dastis M, Rojo N, Alsina MA, Haro I, Panda AK, Mestres C. Biophys. Chem 2004;109:375. [PubMed: 15110935]

33. Ambroggio EE, Kim DH, Separovic F, Barrow CJ, Barnham KJ, Bagatolli LA, Fidelio GD. Biophys. J 2005;88:2706. [PubMed: 15681641]

34. Eisenberg D. Ann. Rev. Biochem 1984;53:595. [PubMed: 6383201]

35. Eisenberg D, Weiss RM, Terwilliger TC. Nature 1982;299:371. [PubMed: 7110359]

36. Dathe M, Wieprecht T. Biochim. Biophys. Acta 1999;1462:71. [PubMed: 10590303]

37. Bettio A, Beck-Sickinger AG. Biopolymers 2002;60:420. [PubMed: 12209475]

38. Seelig, A.; Seelig, J. Encyclopedia of Physical Science and Technology. 9. Academic Press; San Diego: 2002. Membrane structure.; p. 355

39. Chang PJ, Noelken ME, Kimmel JR. Biochemistry 1980;19:1844. [PubMed: 7378377]

40. Blume A. Biochim. Biophys. Acta 1979;557:32. [PubMed: 549642]

41. Marsh D. Biochim. Biophys. Acta 1996;1286:183. [PubMed: 8982283]

42. Reynaud JA, Grivet JP, Sy D, Trudelle Y. Biochemistry 1993;32:4997. [PubMed: 8494875]

J Phys Chem B. Author manuscript; available in PMC 2008 September 26. 


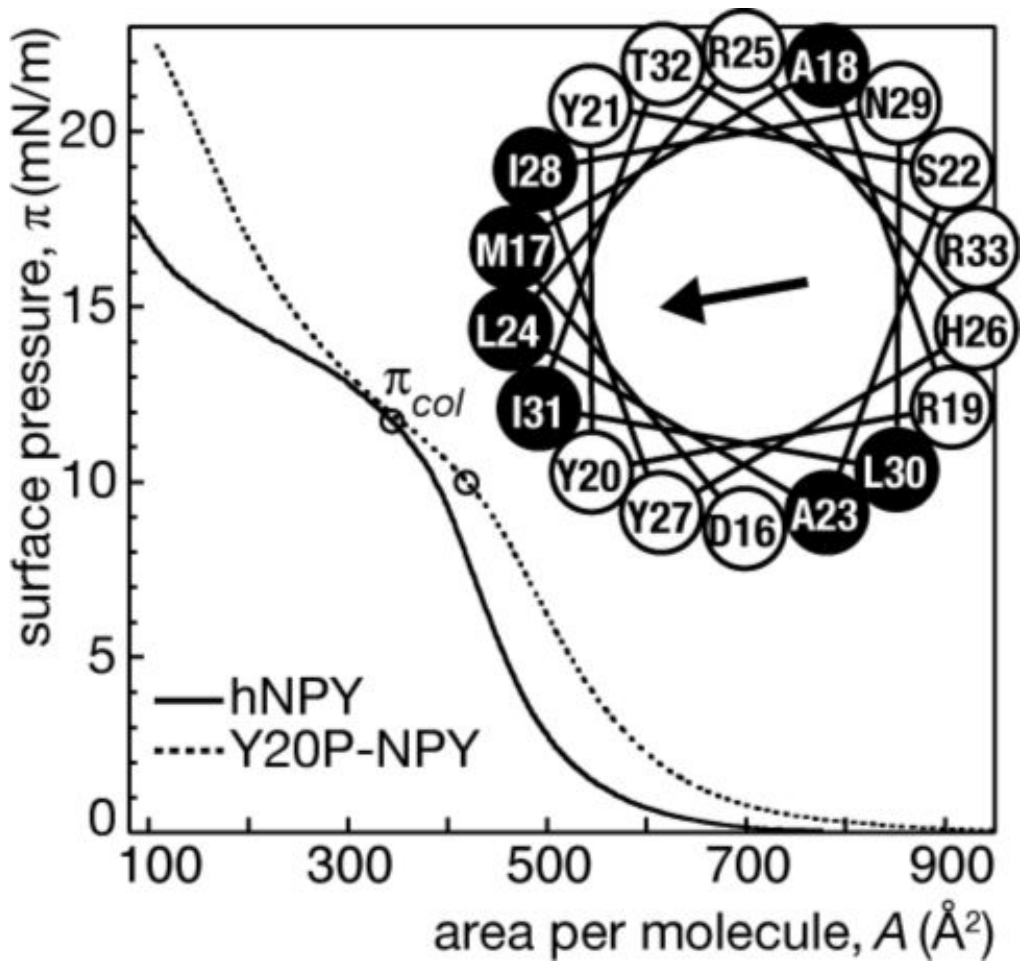

Figure 1.

$\pi-A$ relations of pure peptide, hNPY and Y20P-NPY, on water surfaces at $20^{\circ} \mathrm{C}$. The inset shows a wheel representation of the $\alpha$-helix for hNPY between positions 16 and 33 where the helix is best defined according to NMR results ${ }^{6}$ (black: hydrophobic residues, white: hydrophilic residues) and the associated hydrophobic moment. 


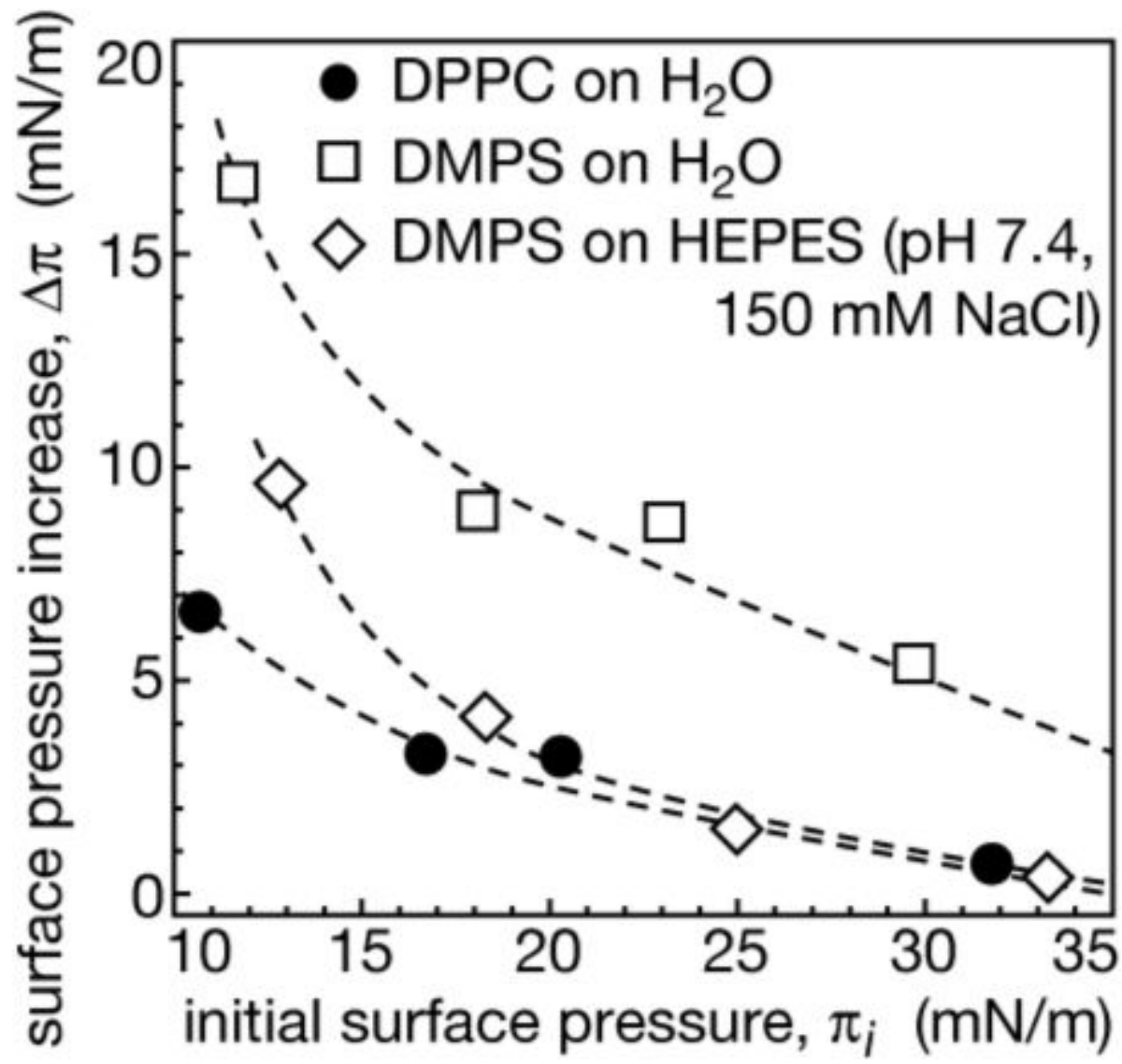

Figure 2.

Surface pressure increase, $\Delta \pi$, of preformed lipid monolayers upon hNPY injection into the subphase as a function of initial pressure, $\pi_{i}$. Lines are guides for the eye. 

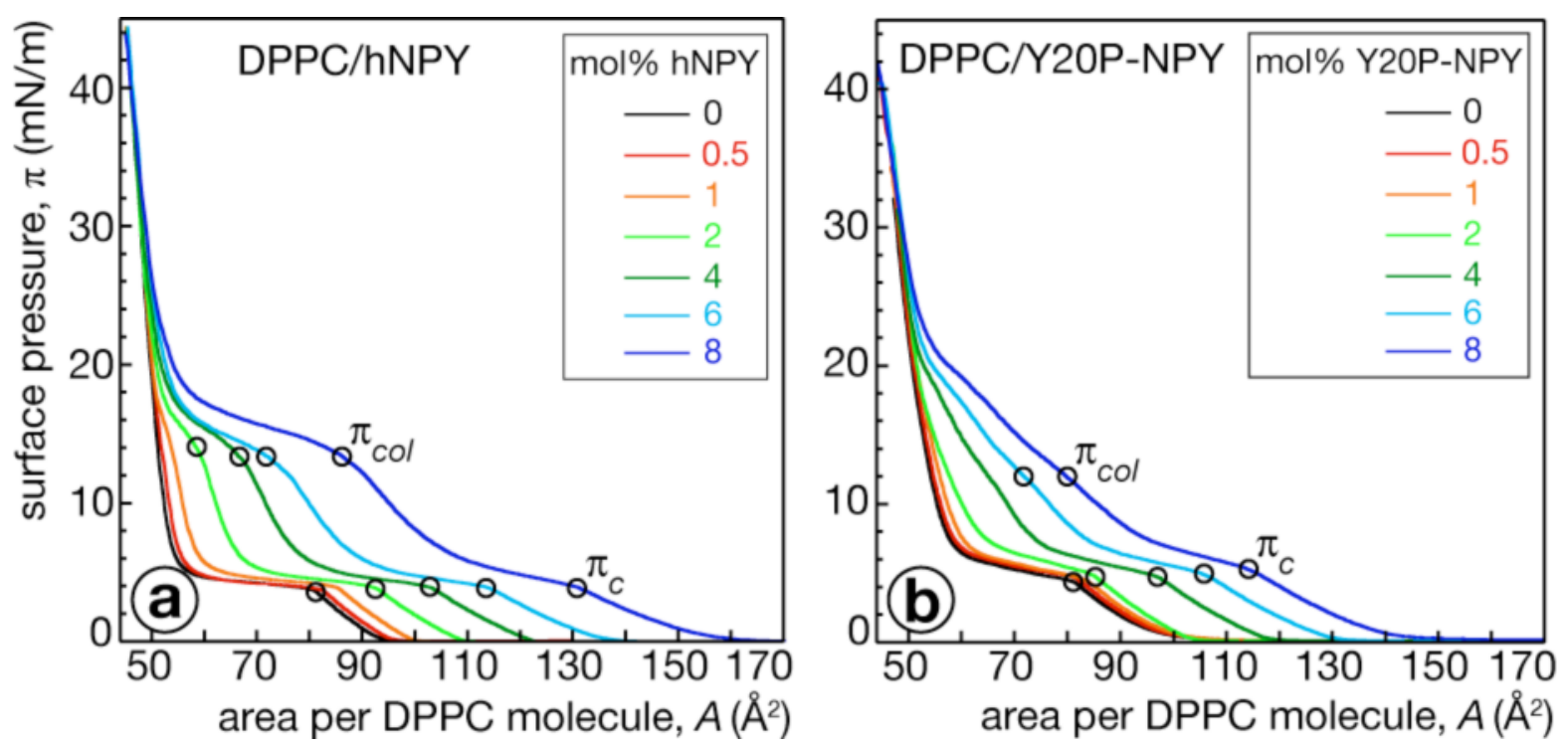

Figure 3.

$\pi$-A isotherms $\left(T=20^{\circ} \mathrm{C}\right)$ of DPPC monolayers with different concentrations of (a) hNPY and (b) Y20P-NPY on water subphases. 

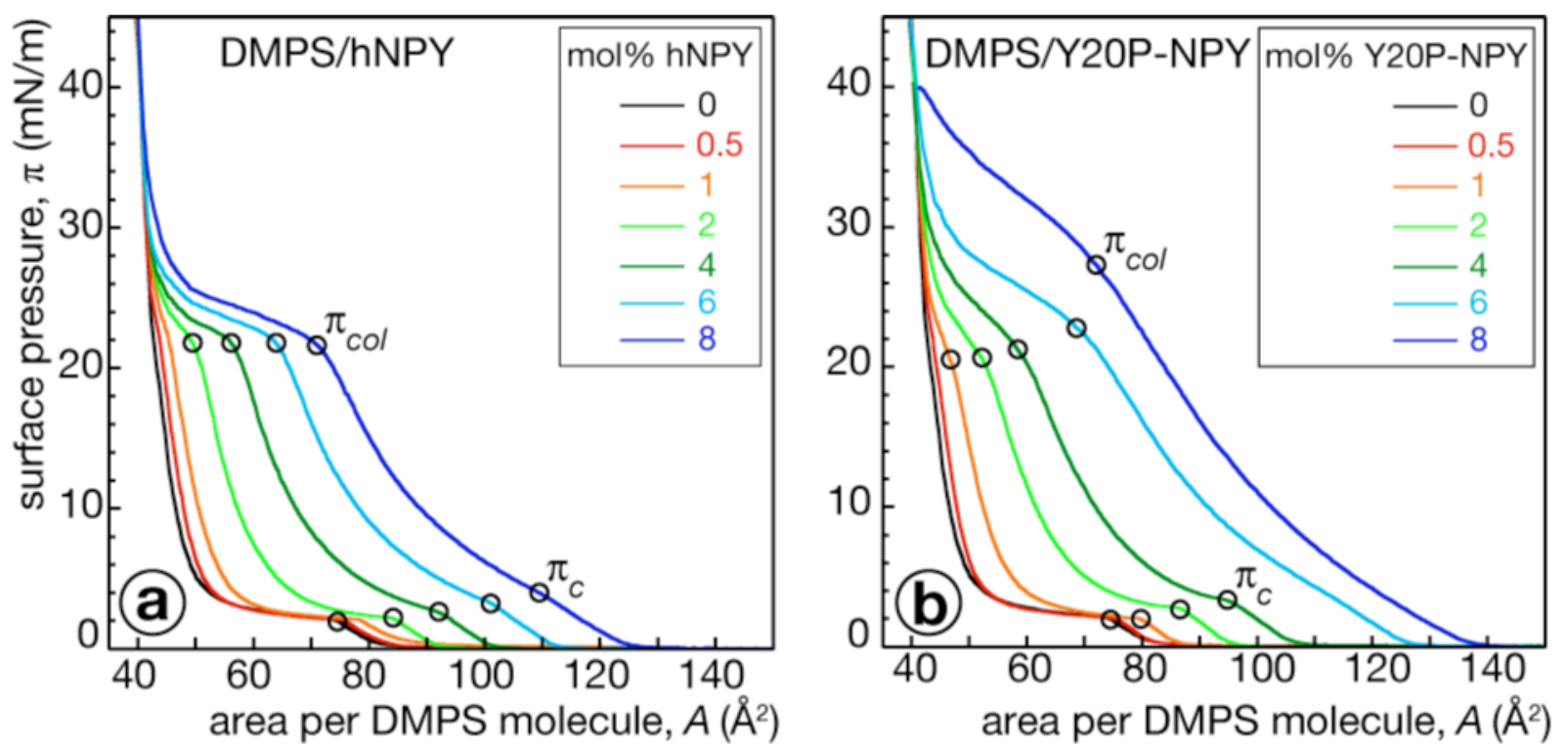

Figure 4.

$\pi$-A isotherms $\left(T=20^{\circ} \mathrm{C}\right)$ of DMPS monolayers with different concentrations of (a) hNPY and (b) Y20P-NPY on water subphases. 


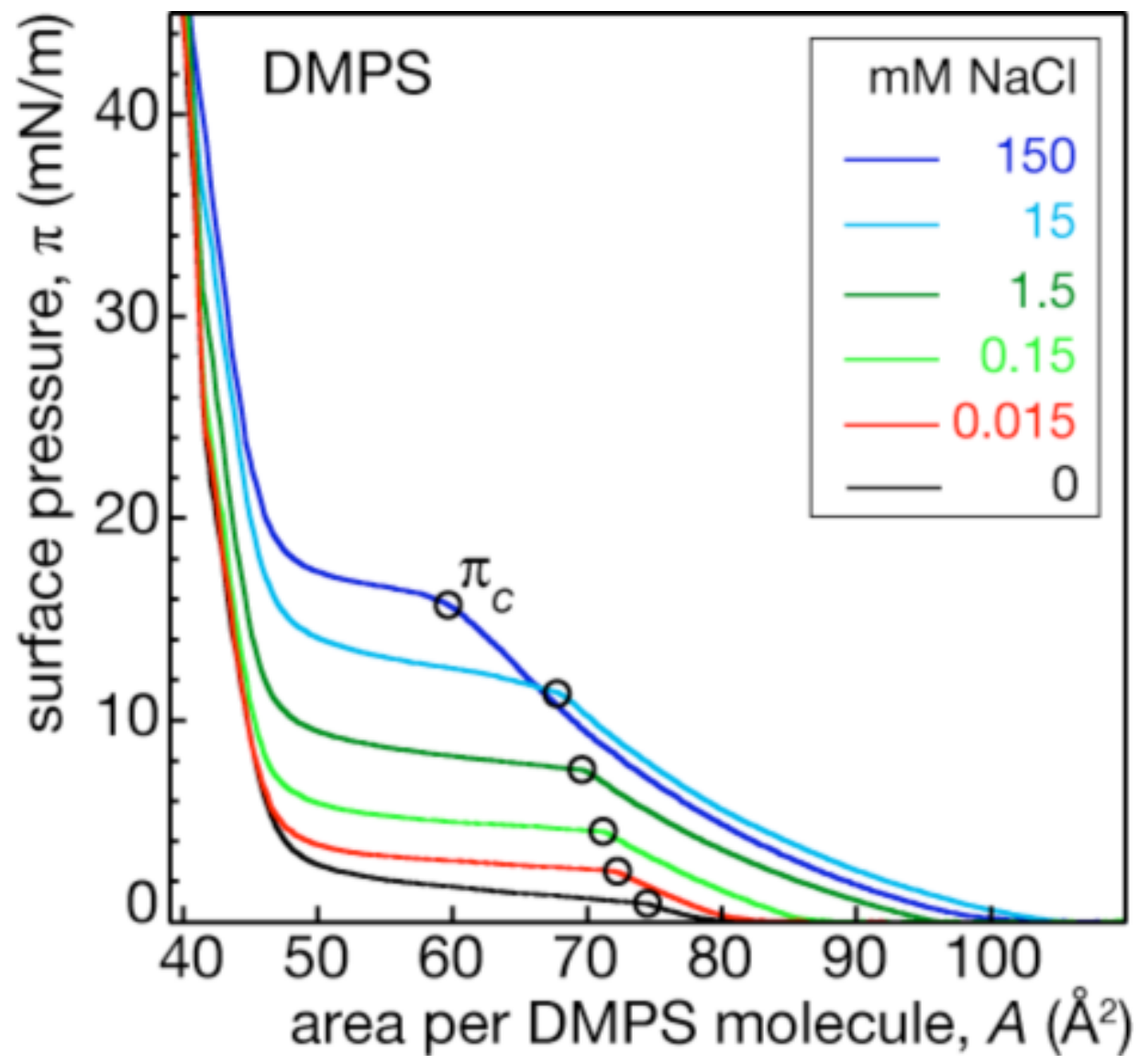

Figure 5.

$\pi$-A isotherms $\left(T=20^{\circ} \mathrm{C}\right)$ of DMPS monolayers on water subphases with different $\mathrm{NaCl}$ concentrations. 


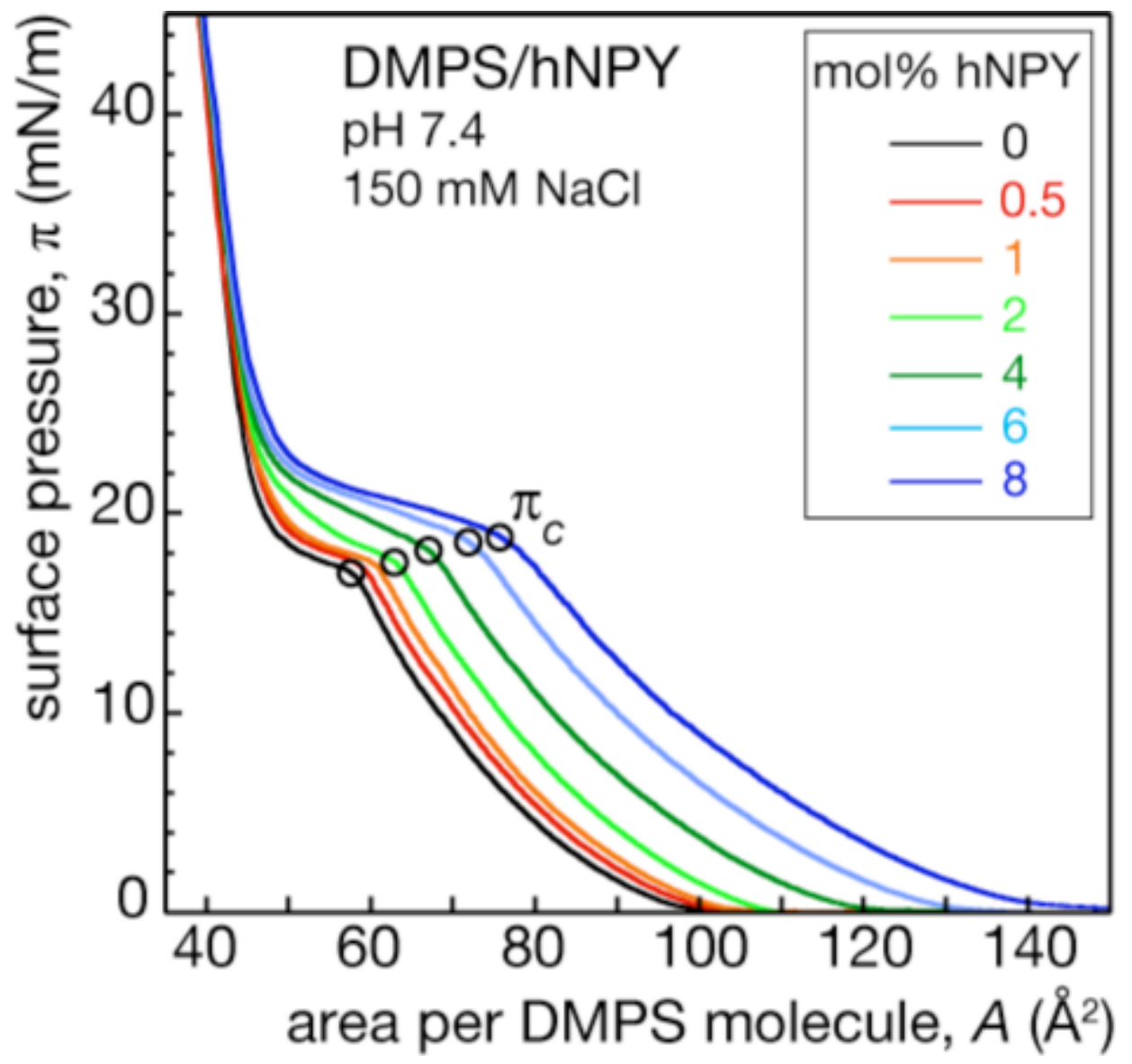

Figure 6.

$\pi$-A isotherms $\left(T=20^{\circ} \mathrm{C}\right)$ of DMPS monolayers on buffer (10 mM HEPES, $\mathrm{pH} 7.4,150 \mathrm{mM}$ $\mathrm{NaCl}$ ) with different concentrations of hNPY. 


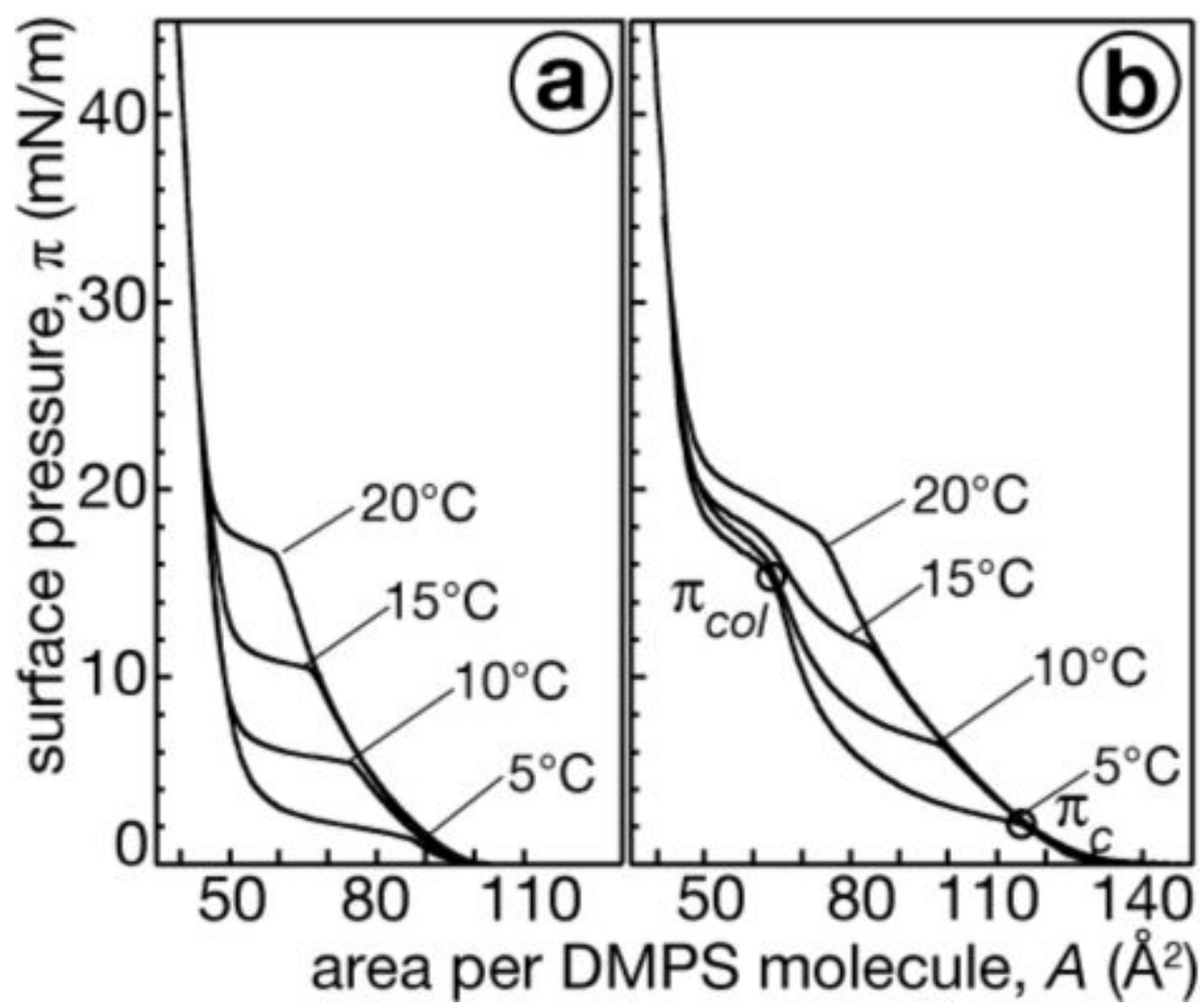

Figure 7.

$\pi$-A isotherms of monolayers from (a) DMPS and (b) DMPS with 4 mol\% hNPY on buffer (10 mM HEPES, pH 7.4, $150 \mathrm{mM} \mathrm{NaCl}$ ). 

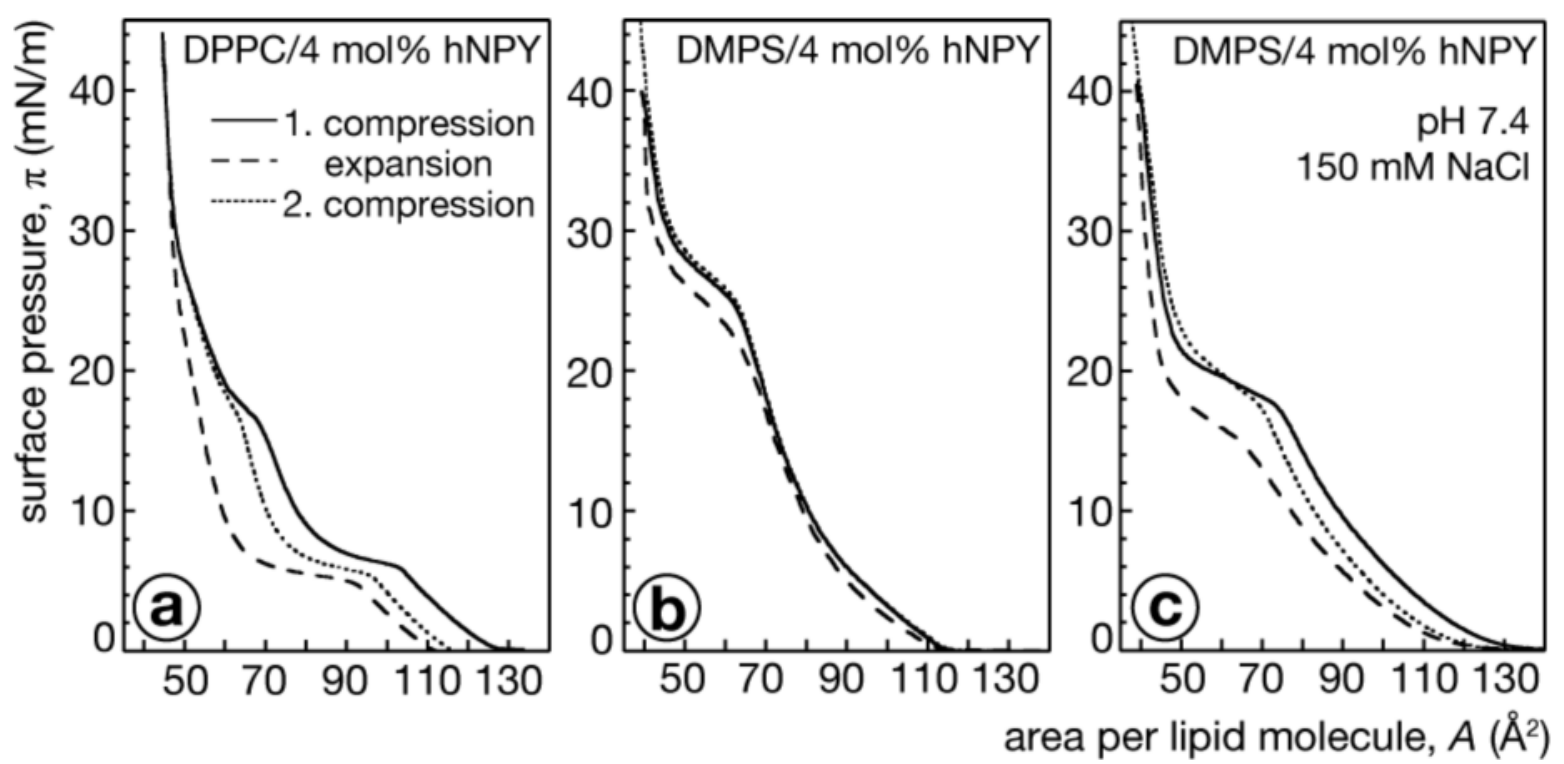

Figure 8. Compression-expansion cycles $\left(T=20^{\circ} \mathrm{C}\right)$ of lipid/hNPY monolayers

(a) DPPC with $4 \mathrm{~mol} \% \mathrm{hNPY}$ on water subphase,

(b) DMPS with 4 mol\% hNPY on water subphase,

(c) DMPS with 4 mol\% hNPY on buffer (10 mM HEPES, pH 7.4, $150 \mathrm{mM} \mathrm{NaCl}$ ). 


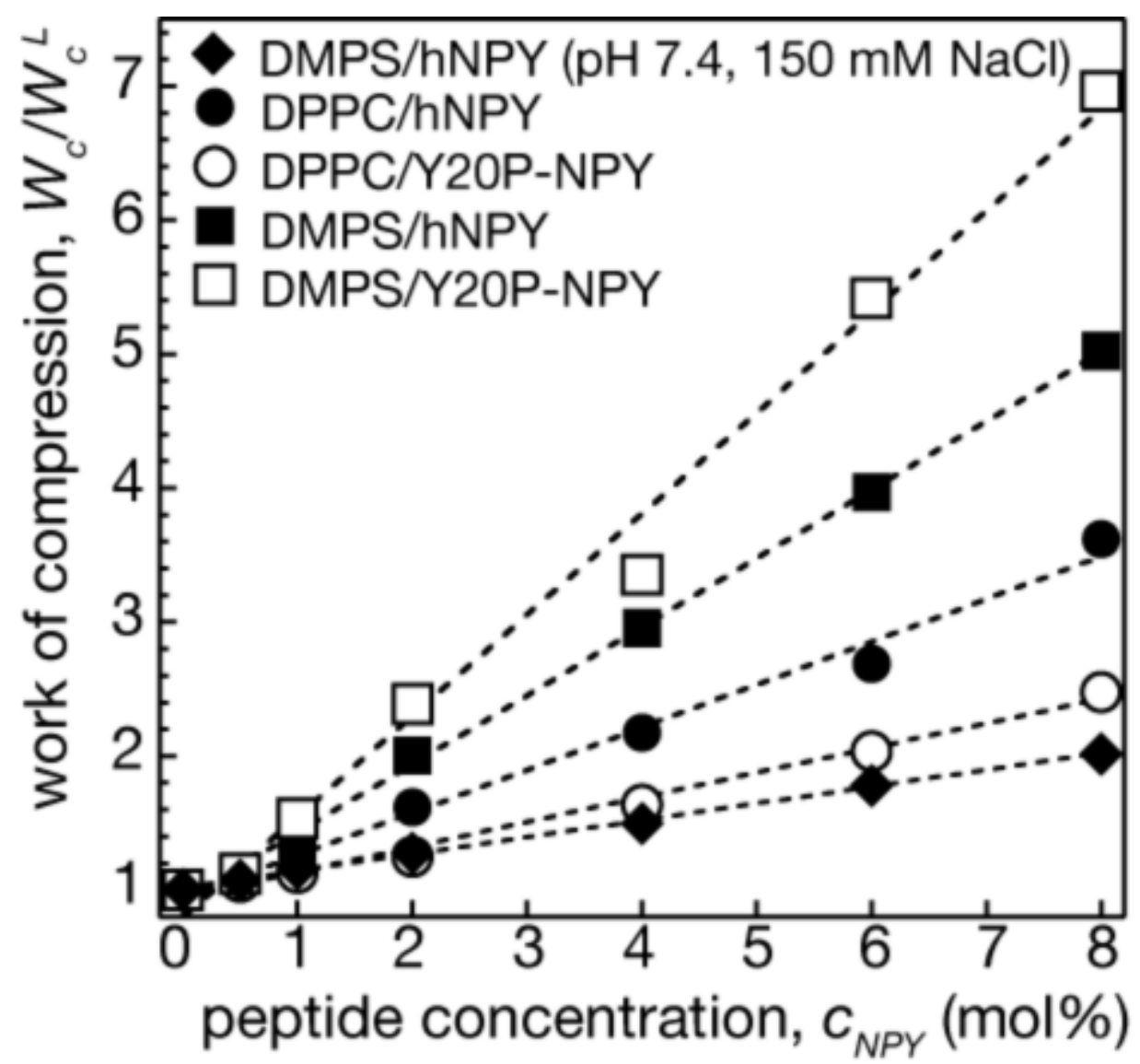

Figure 9.

Work of compression, $W_{c} / W_{c}{ }^{L}$, as a function of peptide concentration, $c_{N P Y}$. Lines are guides for the eye. 


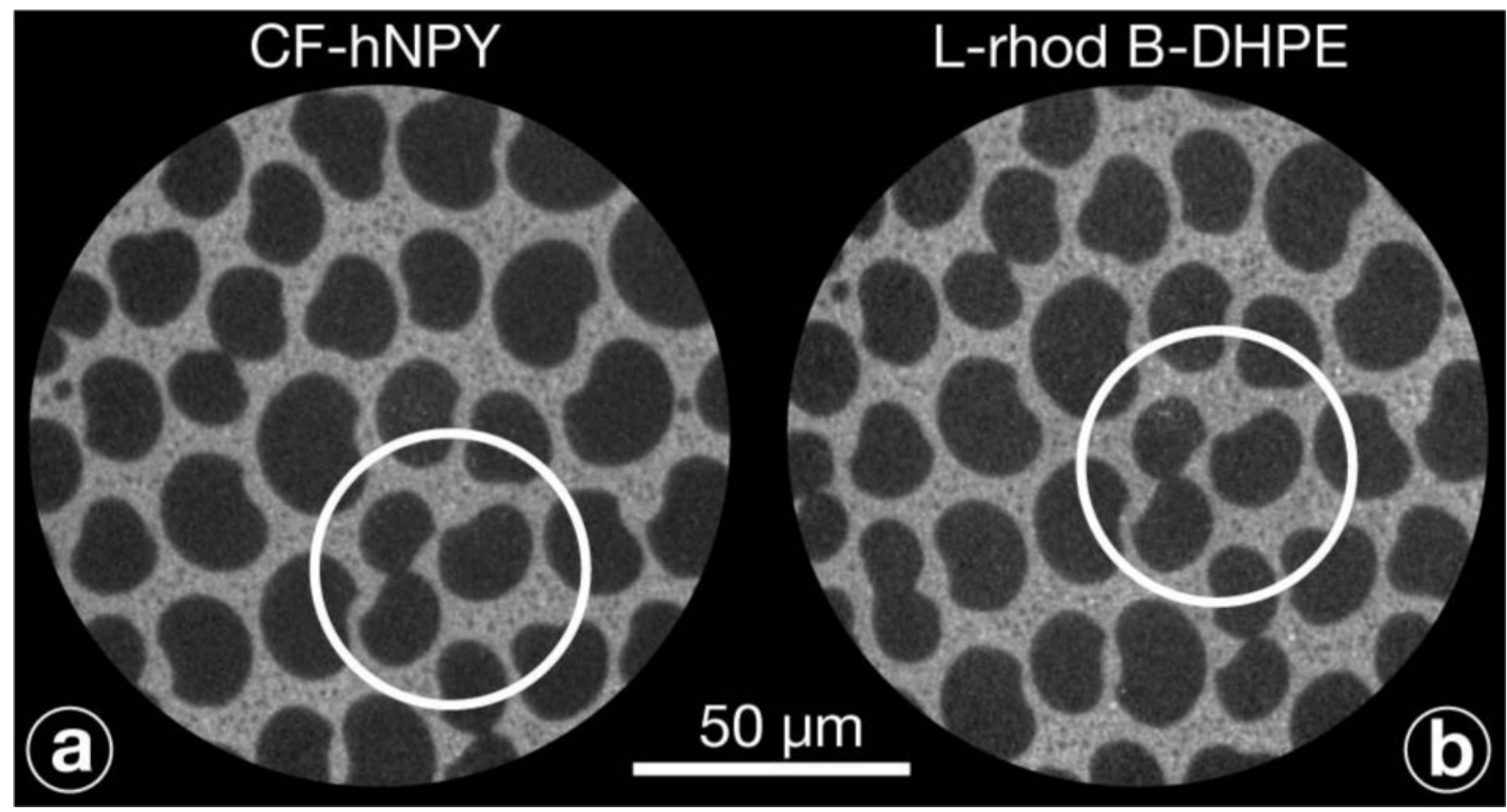

Figure 10.

Dual label fluorescence microscopy of a DPPC monolayer $\left(T=20^{\circ} \mathrm{C}, \pi=17 \mathrm{mN} / \mathrm{m}\right)$ with 8 mol\% hNPY. (a) Fluorescence of CF-hNPY (10\% of total peptide labeled), (b) fluorescence of L-rhod B-DHPE ( $0.4 \%$ with respect to total lipid). White circles mark the same surface feature of the monolayer. 

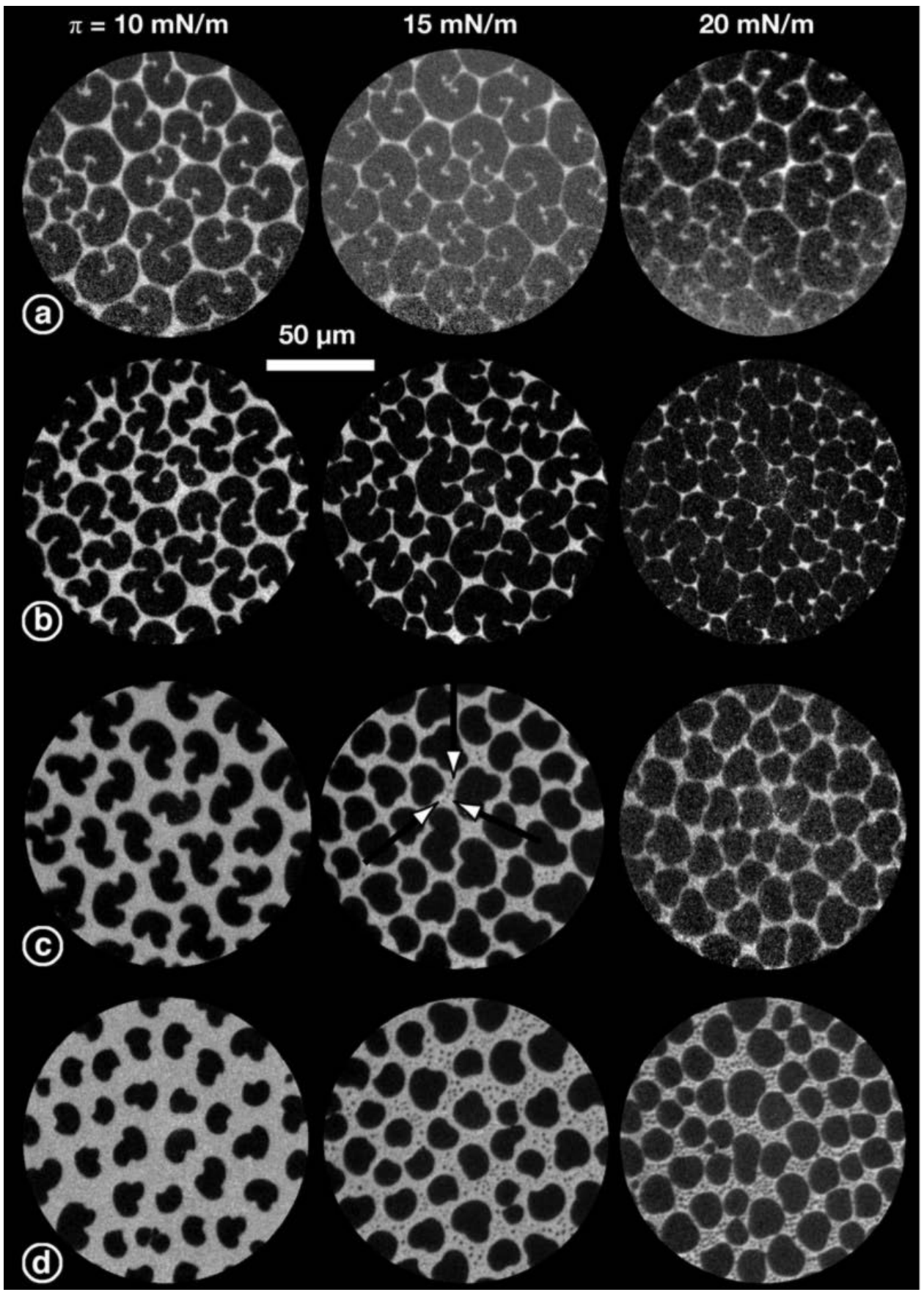

Figure 11.

Fluorescence micrographs of DPPC monolayers on water subphases $\left(T=20^{\circ} \mathrm{C}\right)$ at various surface pressures and with different hNPY concentrations (a: pure lipid, b: $2 \mathrm{~mol} \%$, c: $5 \mathrm{~mol}$ $\%$, d: $8 \mathrm{~mol} \%$ of peptide). Arrows indicate the first appearance of non-fluorescent NPY aggregates in the monolayer with $5 \mathrm{~mol} \%$ of peptide. All images at higher surface pressure and/or higher peptide concentrations show similar aggregates. 

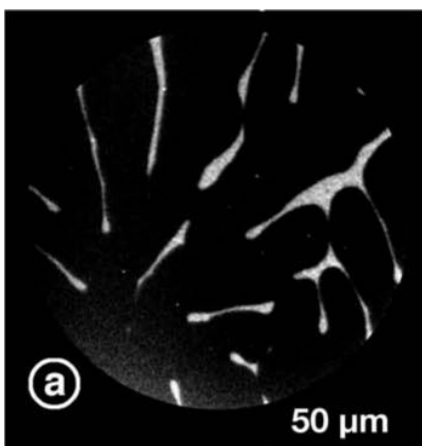

(b)
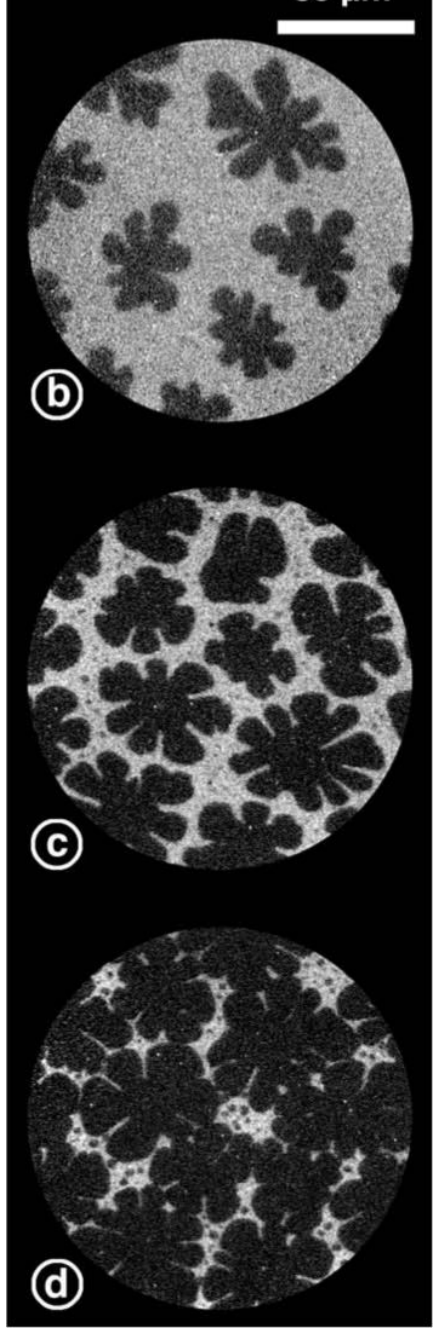

Figure 12.

Fluorescence images of DMPS monolayers on water. $T=20^{\circ} \mathrm{C}$. (a) No peptide, $\pi=4 \mathrm{mN} / \mathrm{m}$. (b) - (d) DMPS with $2 \mathrm{~mol} \% \mathrm{hNPY}$ at $\pi=4,20$ and $25 \mathrm{mN} / \mathrm{m}$, respectively. 